\title{
Overview of this issue: pharmacovigilance, what is new?
}

\author{
Linda Gore Martin ${ }^{1} \cdot$ Yolande Hanssens $^{2} \cdot$ Vibhu Paudyal $^{3}$
}

Published online: 21 August 2018

(c) Springer Nature Switzerland AG 2018

Pharmacovigilance, usually defined with the World Health Organization (WHO) definition of "the science and activities relating to the detection, assessment, understanding and prevention of adverse effects or any other medicine-related problems," [1] is a mandate for the pharmaceutical industry, including Medication Authorisation Holders (MAHs), in most developed countries, but this is not the case for all countries. The International Federation Pharmaceutical Manufacturers \& Associations (IFPMA) has a statement on their website regarding the importance of pharmacovigilance [2]. It should also be considered the responsibility of all governments and health care providers (HCPs) in the interest of the public's health; a clearer role for the public is being established. This special issue of the International Journal of Clinical Pharmacy looks at the current state of pharmacovigilance from different countries and provides some insight into the future. It also explores some special patient populations.

Fornasier et al. [3] presents an overview of the history of pharmacovigilance, while Baldo et al. [4] offers a guide to the terminology. The definitions of pharmacovigilance used by the authors are broad or narrow interpretations of the WHO definitions for adverse drug reactions (ADRs) and adverse drug events (ADEs). These definitions can limit pharmacovigilance programs to ADRs or broaden them to include medication errors, inappropriate use, counterfeiting, quality issues and lack of effectiveness. Causality is always an issue; Behera et al. [5] compare different methods of assessment.

The European Medicines Agency (EMA) [6], working closely with WHO and the United States' Food and Drug Administration (FDA), has established good

Linda Gore Martin

linda.martin@uwyo.edu

1 University of Wyoming School of Pharmacy, Laramie Wyoming, USA

2 Hamad Medical Corporation Pharmacy, Doha, Qatar

3 University of Birmingham, Birmingham, UK pharmacovigilance practices. ${ }^{1}$ The range of compliance with these guidelines is very good in many developed countries but may be non-existent in the developing nations, representing a large percentage of the world's population. Eight working groups identified and discussed this and numerous other issues at a 2016 Oman meeting of the WHO Programme for International Drug Monitoring [7]. Olsson comments on the role of the International Society of Pharmacovigilance [8]. Francescon et al. and Baldo et al. [9, 10] comment on pharmacovigilance in oncology and regulations relative to oncology drugs. Al Hail et al. [11] present the progress of a pharmacovigilance system in Qatar while Zhao et al. [12] present on the status in China.

No country has a perfect pharmacovigilance system. This is even more true as the system applies to over-the-counter and veterinary drugs as well as the aspects included in the broader interpretation. Elshafie et al. [13] presents the concern related to the common practice of self-medication in developing nations. This phenomenon is not restricted to low income population, with the Internet and medical tourism/ travel being used extensively [14]. Li et al. [15] investigated anaphylaxis related to traditional Chinese medicine, compounds usually not included in most databases. The pharmacovigilance of rare diseases is even more complicated, since the number of reports will be extremely low. Chaumais et al. [16] describe a solution for this challenge.

Clinical pre- and post-authorization studies are the primary source of ADRs reports early in the product life cycle. Spontaneous reports become more important in the later stages of the cycle. Concerns about the ability and responsibility to collect data on generic versions have been raised [17]. Historically, most information outside of studies has come from spontaneous reports from HCPs; although pharmacists have been reporting for years, expanding this role in many countries is critical. Coulter [18] reports on the role

\footnotetext{
1 The links to the EMA website in some of the papers in this issue are now incorrect, possibly secondary to the move related to Brexit. The pharmacovigilance page with active links can be accessed as follows: http://www.ema.europa.eu/ema/index.jsp?curl=pages/ regulation/general/general_content_000258.jsp\&mid=WC0b01ac05 $80 \mathrm{~b} 18 \mathrm{c} 76$
} 
of the pharmacist for renal patients and Fornasier et al. [19] report on their role in oncology. Laven et al. [20], Li [21] and Assen Seid [22] studied the current status of pharmacist knowledge, attitudes and participation. However, reporting by the public, as presented by Inácio et al. [23], is starting to become more frequent and strategies to incorporate HCPs with the public reports are more accepted. Jose [24] presents potential negative outcomes of informing patients about side effects; whether being informed increases reporting needs to be explored. The serious problem is that spontaneous reporting is very low for either group; barriers to reporting continue to exist.

A drug registry (consisting of information on multiple facets of the drug including safety) is normally maintained by the reference drug MAH throughout the life cycle (from discovery to end of product life); including for biologicals. Registries from outside industry are also important data collection methods for information such as on drugs in pregnancy, oncology, and rare diseases. AlSaad et al. [25] present a case report that demonstrates a need for pregnancy registries. Lupattelli et al. [26] explore the use of registries and other sources of real-world data on the effects of psychotropics in pregnancy. Other sources of data, including health system records, were used by Wall et al. and Gonzales [27, 28].

The use of large databases such as for pharmacovigilance systems and the storage of national, regional or organizational health records is an increasing source of information. The major systems are VigiBase, the WHO Program for International Drug Monitoring; EudraVigilance, the EMA system for European Economic Area members; and FAERS/ VAERS, the FDA pharmacovigilance reporting systems. Countries also have their own systems. At least 130 countries submit data to Vigibase, in an attempt to create a global system [29]. Algorithms, such as that used by Zhao et al. [30] and rule-based data mining are being used to identify ADRs in those large databases. Artificial intelligence may be able to make this process automatic. The use of social media, especially by patients, to post information on drug events is now a major source of data [31]. Controversy as to the ethical utilization of these sources and other "big data" may limit access. The balance of a global system versus country/regional systems needs to be explored [13]. Elshafie et al. [32], in the second paper, presents the progress and continued needs for the developing nations. Many studies employing these databases and registries use proxies to identify ADRs; harmonization of the systems is important to avoid missing these reactions. Aquiar et al. [33] studied the use of proxies in oncology registries. Modig and Elmståhl [34] used a population database to identify use of nonsteroidal anti-inflammatory drugs in those at risk for renal dysfunction, Ye et al. [35] used another national database to identify amiodarone-induced liver disease. Increased use of these sources for signaling and monitoring of ADRs is expected. Biomarkers that may eventually be included in the databases could improve identifying those at risk. Claus [36] asks whether the process is cost-effective.

This special issue presents a variety of commentaries and studies on the status of pharmacovigilance. Future studies are needed on the use of genetic testing, big data, artificial intelligence and block chain technology to understand if they provide solutions or add more ethical and other challenges to the pharmacovigilance process. Industry and regulatory bodies are important partners, but innovation comes from the researchers and practitioners. The pharmacist is in the ideal environment to work with patients and organizations to create a better pharmacovigilance world.

Funding None.

Conflicts of interest None.

\section{References}

1. World Health Organization. The importance of pharmacovigilance-safety monitoring of medicinal products. WHO Collaborating Centre for International Drug Monitoring, Geneva, Switzerland. 2002. http://apps.who.int/medicinedocs/en/d/Js4893e/. Accessed 21 July 2018.

2. International Federation Pharmaceutical Manufacturers \& Associations. Why is pharmacovigilance important. Geneva: IFPMA. 2015. https://www.ifpma.org/subtopics/pharmacovigiliance/. Accessed 20 July 2018.

3. Fornasier G, Francescon S, Leone R, Baldo P. An historical overview over pharmacovigilance. Int J Clin Pharm. 2018. https://doi. org/10.1007/s11096-018-0657-1.

4. Baldo P, Francescon S, Fornasier G. Pharmacovigilance workflow in Europe and Italy and pharmacovigilance terminology. Int J Clin Pharm. 2018. https://doi.org/10.1007/s11096-018-0711-z.

5. Behera SK, Das S, Xavier AS, Velupula S, Sandhiya S. Comparison of different methods for causality assessment of adverse drug reactions. Int J Clin Pharm. 2018. https://doi.org/10.1007/s1109 6-018-0694-9.

6. European Medicines Agency. Pharmacovigilance. London: EMA. 2018. http://www.ema.europa.eu/ema/index.jsp?curl=pages/regul ation/general/general_content_000258.jsp\&mid=WC0b01ac05 80b18c76. Accessed 20 July 2018.

7. World Health Organization. 39th annual meeting of representatives of national pharmacovigilance centres participating in the WHO Programme for International Drug Monitoring Muscat, Oman 14-17 November 2016. http://www.who.int/medicines/ regulation/medicines-safety/publications/39pvnc.pdf?ua $=1$. Accessed 21 July 2018.

8. Olsson S, Harrison-Woolrich M. The role and strategy of ISoP in global pharmacovigilance. Int J Clin Pharm. 2018. https://doi. org/10.1007/s11096-018-0708-7.

9. Baldo P, Fornasier G, Ciolfi L, Sartor I, Francescon S. Pharmacovigilance in oncology. Int J Clin Pharm. 2018. https://doi. org/10.1007/s11096-018-0706-9.

10. Francescon S, Fornasier G, Baldo P. EU pharmacovigilance regulatory requirements for anticancer biosimilar monoclonal antibodies. Int J Clin Pharm. 2018. https://doi.org/10.1007/s1109 6-018-0709-6. 
11. Al Hail M, Elkassem W, Hamad A, Abdulrouf P, Thomas B, Stewart D. Overview of pharmacovigilance practices at the largest academic healthcare system in the State of Qatar. Int J Clin Pharm. 2018. https://doi.org/10.1007/s11096-018-0629-5.

12. Zhao Y, Wang T, Li G, Sun S. Pharmacovigilance in China: development and challenges. Int J Clin Pharm. 2018. https://doi. org/10.1007/s11096-018-0693-x.

13. Elshafie S, Zaghloul I, Roberti AM. Pharmacovigilance in developing countries (part I): importance and challenges. Int J Clin Pharm. 2017. https://doi.org/10.1007/s11096-017-0570-z.

14. Al Khaja KA, Sequeira RP, Damanhori AH. Polypharmacy associated with medical tourism: a critique on drug therapy. Int J Clin Pharm. 2011;33:61-5. https://doi.org/10.1007/s1109 6-010-9477-7.

15. Li X, Thai S, Lu W, Sun S, Tang H, Zhai S, Wang T. Traditional Chinese medicine and drug-induced anaphylaxis: data from the Beijing pharmacovigilance database. Int J Clin Pharm. 2018. https ://doi.org/10.1007/s11096-018-0699-4.

16. Chaumais M, Caroline O'Connell C, Savale L, Guignabert C, Perros F, Jaïs X, et al. Pharmacovigilance in a rare disease: example of the VIGIAPATH program in pulmonary arterial hypertension. Int J Clin Pharm. 2018. https://doi.org/10.1007/s1109 6-018-0712-y.

17. Tawde SA. Generic pharmaceuticals: is pharmacovigilance required? J Pharmacovigil. 2014;2:e124. https://doi. org/10.4172/2329-6887.1000e124.

18. Coulter CV. The role of the suspicious renal pharmacist in identifying unusual adverse drug reactions-why this is not a small problem. Int J Clin Pharm. 2018. https://doi.org/10.1007/s1109 6-018-0660-6.

19. Fornasier G, Taborelli M, Francescon S, Polesel J, Aliberti M, De Paoli P, Baldo P. Targeted therapies and adverse drug reactions in oncology: the role of clinical pharmacist in pharmacovigilance. Int J Clin Pharm. 2018. https://doi.org/10.1007/s11096-018-0653-5.

20. Laven A, Schmitz K, Franzen WH. Reporting adverse drug reactions: contribution, knowledge and perception of German pharmacy professionals. Int J Clin Pharm. 2018. https://doi. org/10.1007/s11096-018-0671-3.

21. Li R, Curtain C, Bereznicki L, Zaidi STR. Community pharmacists' knowledge and attitudes toward reporting adverse drug reactions in Australia: a cross-sectional survey. Int J Clin Pharm. 2018. https://doi.org/10.1007/s11096-018-0700-2.

22. Mohammed Assen Seid M, Emagn Kasahun A, Markos Mante B, Naji Gebremariam S. Health care professionals' knowledge, attitude, and practice toward adverse drug reaction (ADR) reporting at the health center level in Ethiopia. Int J Clin Pharm. 2018. https://doi.org/10.1007/s11096-018-0682-0.

23. Inácio $\mathrm{P}$, Cavaco A, Airaksinen M. Current trends in pharmacovigilance: value and gaps of patient reporting. Int J Clin Pharm. 2018. https://doi.org/10.1007/s11096-018-0689-6.
24. Jose J, Al Hajri L. Potential negative impact of informing patients about side effects: a systematic review. Int J Clin Pharm. 2018. https://doi.org/10.1007/s11096-018-0716-7.

25. AlSaad D, Lee BH, Al-Obaidly S. Finasteride use during pregnancy and early neonatal outcome: a case report. Int J Clin Pharm. 2018. https://doi.org/10.1007/s11096-018-0661-5.

26. Lupattelli A, Spigset O, Nordeng H. Learning the effects of psychotropic drugs during pregnancy using real-world safety data: a paradigm shift toward modern pharmacovigilance. Int J Clin Pharm. 2018. https://doi.org/10.1007/s11096-018-0672-2.

27. Wall GC, Taylor MJ, Smith HL. Prevalence and characteristics of hospital inpatients with reported fluoroquinolone allergy. Int J Clin Pharm. 2018. https://doi.org/10.1007/s11096-018-0613-0.

28. Martin Arias LH, Martin Gonzales A, Sanz Fadrique R, Salgueiro E, Sainz M. Cardiovascular and gastrointestinal safety of selective cyclooxygenase- 2 inhibitors: a case/non-case study. Int J Clin Pharm. 2018. https://doi.org/10.1007/s11096-018-0705-x.

29. World Health Organization. The WHO programme for international drug monitoring. Geneva: WHO. 2018. http://www.who. int/medicines/regulation/medicines-safety/about/drug_monitoring _prog/en/. Accessed 21 July 2018.

30. Zhao Y, Lu H, Thai S, Li X, Hui J, Tang H, Zhai S, Sun L, Wang T. Development and validation of an algorithm to identify drug-induced anaphylaxis in the Beijing Pharmacovigilance Database. Int J Clin Pharm. 2018. https://doi.org/10.1007/s1109 6-018-0594-z.

31. Bousquet C, Dahamna B, Guillemin-Lanne S, et al. The adverse drug reactions from patient reports in social media project: five major challenges to overcome to operationalize analysis and efficiently support pharmacovigilance process. JMIR Res Protoc. 2017;6(9):179. https://doi.org/10.2196/resprot.6463.

32. Elshafie S, Roberti AM, Zaghloul I. Pharmacovigilance in developing countries (part II): a path forward. Int J Clin Pharm. 2018. https://doi.org/10.1007/s11096-017-0588-2.

33. Aguiar JP, Cardoso Borges F, Murteira R, Ramos C, Gouveia $\mathrm{E}$, Passos MJ, et al. Using a cancer registry to capture signals of adverse events following immune and targeted therapy for melanoma. Int J Clin Pharm. 2018. https://doi.org/10.1007/s1109 6-018-0665-1.

34. Modig S, Elmståhl S. Kidney function and use of nonsteroidal anti-inflammatory drugs among elderly people: a cross-sectional study on potential hazards for an at risk population. Int J Clin Pharm. 2018. https://doi.org/10.1007/s11096-018-0598-8.

35. Ye JH, Ho YF, On AW, Chen WW, Huang YM, Huang WI, Tang YW. Trends in reporting drug-associated liver injuries in Taiwan: a focus on amiodarone. Int J Clin Pharm. 2018. https://doi. org/10.1007/s11096-018-0698-5.

36. Claus BOM. Is pharmacovigilance of biologicals cost-effective? Int J Clin Pharm. 2018. https://doi.org/10.1007/s1109 6-018-0695-8. 